\title{
Surface Properties of Powder Injection Moulded Parts Related to Processing Conditions
}

\author{
Berenika Hausnerová ${ }^{1,2}$, Daniel Sanétrník ${ }^{2}$ and Vladimír Pata ${ }^{1}$ \\ ${ }^{1}$ Dept. of Production Engineering, Faculty of Technology, Tomas Bata University in Zlin, nam. T.G.Masaryka 5555, 760 \\ 01 Zlin, Czech Republic, E-mail: hausnerova@utb.cz \\ ${ }^{2}$ Centre of Polymer Systems, University Institute, Tomas Bata University in Zlin, Trida T. Bati 5678, 760 01 Zlin, Czech \\ Republic
}

\begin{abstract}
The surface quality of ceramic items produced via powder injection moulding (PIM) at processing conditions varying in injection moulding temperature and debinding route is investigated. The analysis is performed on aluminium oxide part design containing complicated rotational areas, where a smooth surface of an internal spiral is a critical quality factor. Surface properties of the final sintered parts are examined with the help of a contactless scanner. Then, the obtained surface roughness data are treated with suitable statistical analytical tools in order to reveal the effect of the processing conditions during the PIM process on the final parts. Relating surface properties of final sintered parts to processing parameters might provide a powerful tool to control particular steps of PIM process.
\end{abstract}

Keywords: Quality, Powder injection moulding, Contactless scanning, Roughness evaluation

\section{Introduction}

Powder injection moulding (PIM) is a valuable alternative to traditional metal and ceramic forming methods [1]. Surface properties of the sintered powder injection moulding (PIM) parts have recently gained increasing attention [2]. PIM process consists of four main steps: preparation of ceramic (CIM) or metallic (MIM) feedstocks, their manufacturing via injection moulding followed with debinding and approaching to final sintering.

Although the surface roughness is generally smaller for ceramics than metals due to their relatively smaller powder sizes available, there is an increasing number of applications (especially in $\mu$-PIM [3]), where the surface forces become dominant at the surface-to-volume ratio encountered in ceramic parts. Such forces (e.g. friction, viscous drag and surface tension) are encountered in particular for applications involving fluid flow, surface reaction, wear and lubrication at the interface [4-6].

Currently, surface roughness values in the range of $R \mathrm{a}$ $=0.3-0.6 \mu \mathrm{m}$ and $R \mathrm{z}=2-5 \mu \mathrm{m}$ are reached in $\mu \mathrm{PIM}$, depending on the material and powder particle size $[7,8]$. The best surface qualities obtained were $R \max =2-3 \mu \mathrm{m}$ with ultrafine ceramic powders [9]. Lower values of surface finish are likely to be achieved as the $\mu$ PIM process develops and new advanced feedstock systems are introduced [10].

Surface properties of the sintered powder injection moulding parts are dictated above all by sintering conditions (atmosphere, temperature-time profile and heat flow distribution). Sintering affects the surface roughness of the final part since the roughness of sintered components is the highest surface roughness observed throughout the process chain [11]. However, the effect of debinding conditions on resulting surface roughness has been investigated as well. Liu et al. [5] showed that using higher heating rates during debinding increased the weight loss of rebound $316 \mathrm{~L}$ stainless steel microstructured parts. The debound parts of higher weight loss gave better surface finish after sintering. Comparing the increase of sintering time and temperature, the surface finish improvement was more significant for increasing temperature.

On the other hand, the surface roughness of the mould was shown to have a negligible influence on the surface quality of sintered components. If the surface roughness $R$ a of the mould, the green parts and the sintered parts were compared for different sintering conditions, it has turned out that whilst the roughness of the green part increased slightly compared to the mould roughness, the surface roughness values of the sintered part was orders of magnitude higher than the mould values [4].

The weak point of majority studies concerning the investigation of surface properties generally lies in the leak of reliable quantification methods and their employment [12-16]. Therefore, the intent of this paper is to present the quantitative study of sintered ceramic parts at critical conditions, where the statistical tools available will be tested and compared. For this purpose, the possible effect of injection moulding temperature and debinding method were selected to demonstrate the sensitivity of the approaches employed. The non-destructive testing [17] has been selected as a proper tool to achieve this task. The additional aim of this article is to find suitable statistical metrological methods describing the properties of samples produced by PIM technology under specified repeatability conditions in accordance with ISO 4287 and ISO 4288.

\section{Experimental}

In this study, highly compressive super ground aluminium oxide (alumina) powder MARTOXID ${ }^{\circledR}$ MR70 (Albemarle Corporation, USA) with a specific surface area (BET) $6-10 \mathrm{~m}^{2} / \mathrm{g}$, bulk density $\sim 0.90 \mathrm{~g} / \mathrm{cm}^{3}$, green density $2.20-2.40 \mathrm{~g} / \mathrm{cm}^{3}$ and fired density $\left(1,600^{\circ} \mathrm{C}, 2 \mathrm{~h}\right)$ $3.80-3.92 \mathrm{~g} / \mathrm{cm}^{3}$ was used to produce the ceramic item containing complicated rotational areas, where a smooth surface of an internal spiral is a critical quality factor (see Fig. 1). 


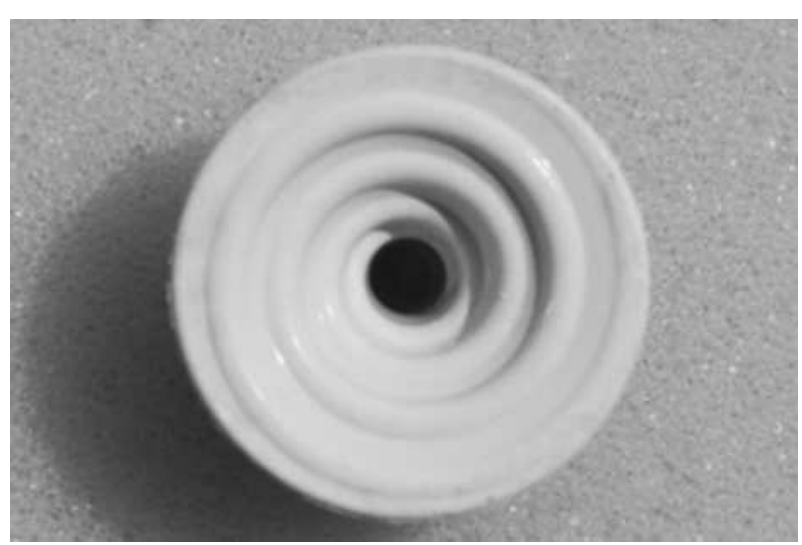

Fig. 1 Design of tested aluminium oxide PIM part

The powder was compounded with a commercial multi-component binder Licomont EK 583-G (Clariant, Switzerland) which is partially water-soluble with a density $1.05-1.15 \mathrm{~g} / \mathrm{cm}^{3}$ and the softening point at $105-115^{\circ} \mathrm{C}$. During mixing in a blade kneader at $160{ }^{\circ} \mathrm{C}$ for $2 \mathrm{~h}$, a surfactant ( $1 \mathrm{wt} . \%$ oleic acid) was added. Subsequently, 60 vol. $\%$ feedstock in the form of pellets was acquired from a single-screw extruder.

Two series of samples were selected differing in $(10 \pm 0.5){ }^{\circ} \mathrm{C}$ in moulding (nozzle) temperatures: $150{ }^{\circ} \mathrm{C}$ (Alu150) and $160{ }^{\circ} \mathrm{C}$ (Alu160), and debinding routes, where $\mathrm{T}$ in the abbreviation means that the samples were debound thermally, and ST stands for combined solvent/thermal binder removal.

Prior to testing the samples were cleaned in a technical gas stream connected to impurities separator. In order to obtain a quantitative analysis, a contactless 3D Chromatic Length Aberration (CLA) scanner (Talysurf 300, Taylor and Hobson, UK) equipped with Talymap ver.5.0.2 software has to be employed. Tested surfaces were subjected to a height measurement over a rectangular area $(1 \mathrm{x} 1) \mathrm{mm}$ with the scanning rate of $100 \mu \mathrm{m} / \mathrm{s}$ and spacing $5 \mu \mathrm{m}$. Filtration of the scanning data was done with the help of Gaussian filter $(0.25 \mathrm{~mm})$ in accordance with ISO 4288.

\section{Results}

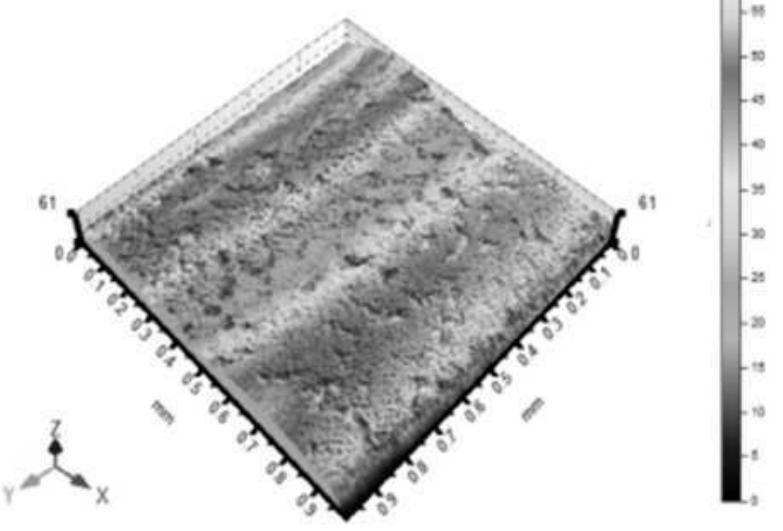

Fig. 2 Example of surface reconstruction from contactless measurement on a 160ST sample

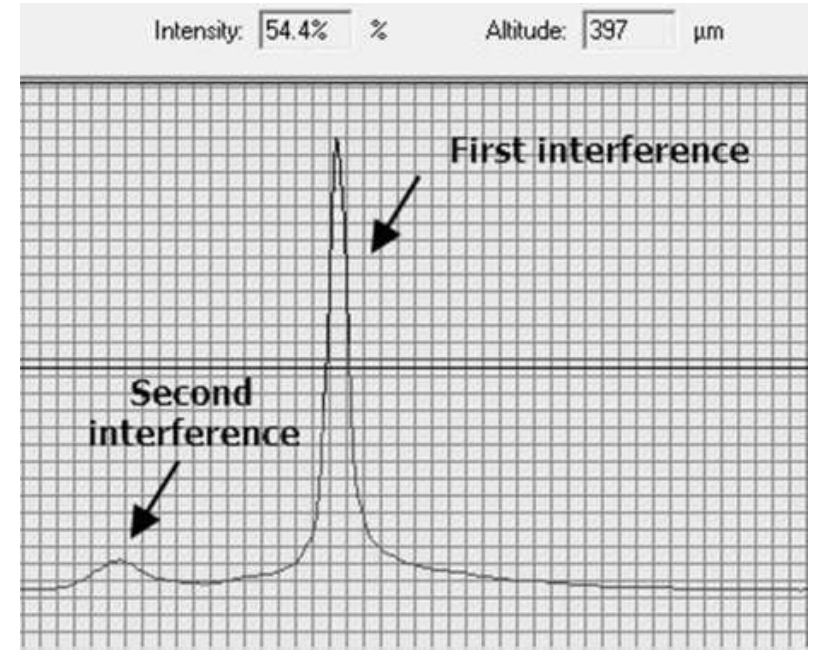

Fig. 3 Interface Detection (FID) measurement mode applied to a $3 D$ surface reconstruction

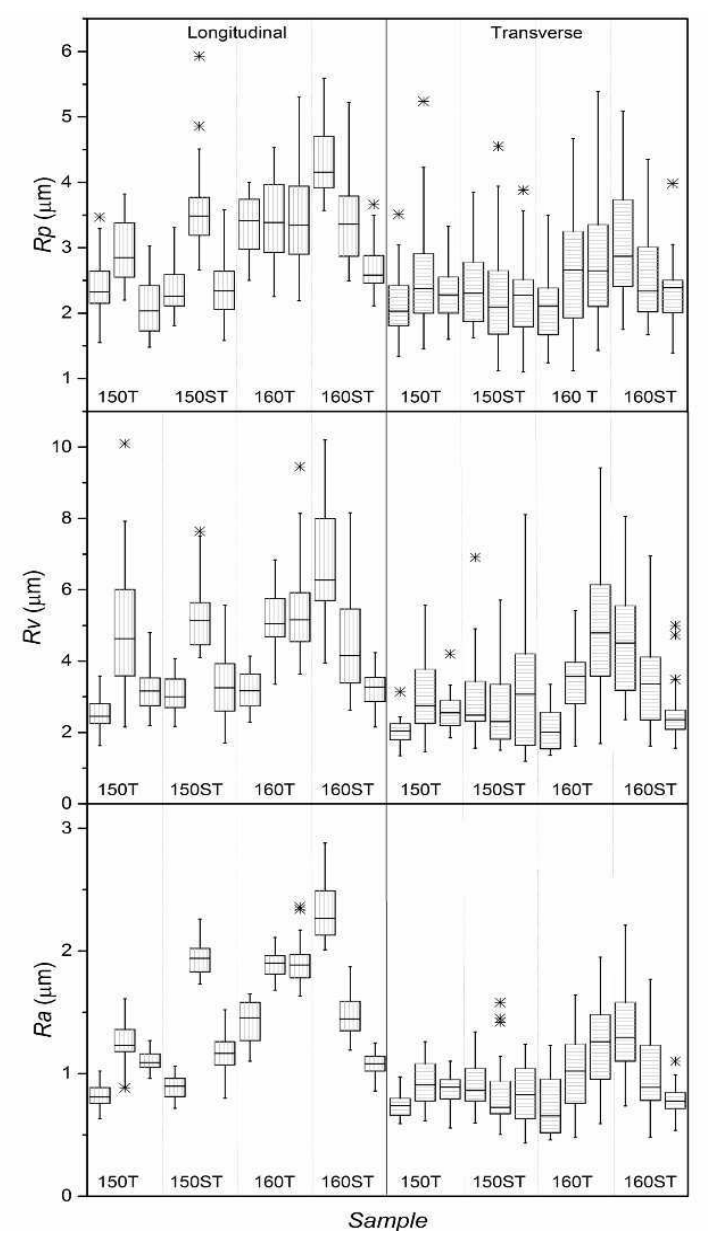

Fig. 4 Box-Plot diagrams of Rp, $R v$, and Ra for the samples molded at $150{ }^{\circ} \mathrm{C}$ and $160^{\circ} \mathrm{C}$ and debound thermally $(150 T, 160 T)$ and solvent/thermally (150ST, 160ST) and scanned in longitudinal and transverse directions

An example of 3D data map obtained from the contactless surface scanning is depicted in Fig. 2. The data supplied is of the form $z=\mathrm{f}(x, y)$, where $z$ is the height of the profile, $x$ stands for the position over the scanning direction, and $y$ corresponds to the number of traces. Then, 
First Interface Detection (FID) was selected as a measurement mode. The software takes into account the height of the first interference (i.e. the upper border of the transparent interference epresented by the first peak in the spectrum), Fig. 3.

Surface mapping data was evaluated from the fracture planes (meaning conversion into series of profiles), where 200 profiles in both $x$ - and $y$-axes were obtained for each sample. Surface parameters $R \mathrm{p}, R \mathrm{v}$, and $R \mathrm{a}$ were treated with Anderson-Darlin normality test $(\alpha=0.95)$ in accordance with ISO 4287. According to this test, the normality of the data was denied on the confidential level of $0.95 \%$. This means that the examined surfaces contain non-random inhomogeneities, which must be detected with a suitable statistical tool serving as a base for the relation of the surface properties to the processing conditions.

Primary statistical evidence might be Box-Plot diagrams of $R \mathrm{p}, R \mathrm{v}$, and $R$ a showing the considerable scatter of the measured data as shown on the example for surface samples injected at 150 and $160{ }^{\circ} \mathrm{C}$, and then debound thermally or solvent/thermally, Fig. 4.

Thus, the next issue is an evaluation of differently processed samples (change of temperature during moulding) when the normality of the data is absent. Kruskal-Wallis statistical approach has been selected as it enables simple analysis of a data to scatter. A zero-hypothesis expects that the particular surface roughness parameters $(R \mathrm{p}, R \mathrm{v}$, $R a)$ have the same median values in the sample groups.

In the following, the Zero-hypothesis for $R a$ parameter of the samples moulded at two different temperatures and debound thermally (150T and $160 \mathrm{~T}$ ) in the longitudinal direction (Fig. 5) is:

- $H_{0}:$ Median $_{R_{a_{l}}}($ Sample $150 T$ number 1$)=$ Median $_{R_{a_{l}}}($ Sample 150T number 2$)=$ Median $_{R_{a_{l}}}$ (Sample 150T number 3$)=$ Median $_{R_{a_{l}}}($ Sample 160T number 1$)=$ $M_{R_{a_{l}}}($ Sample $160 T$ number 2$)=$ $M_{\text {edianR }_{a_{l}}}$ (Sample 160T number3)

- $H_{A}: N O N$

- $p=0$

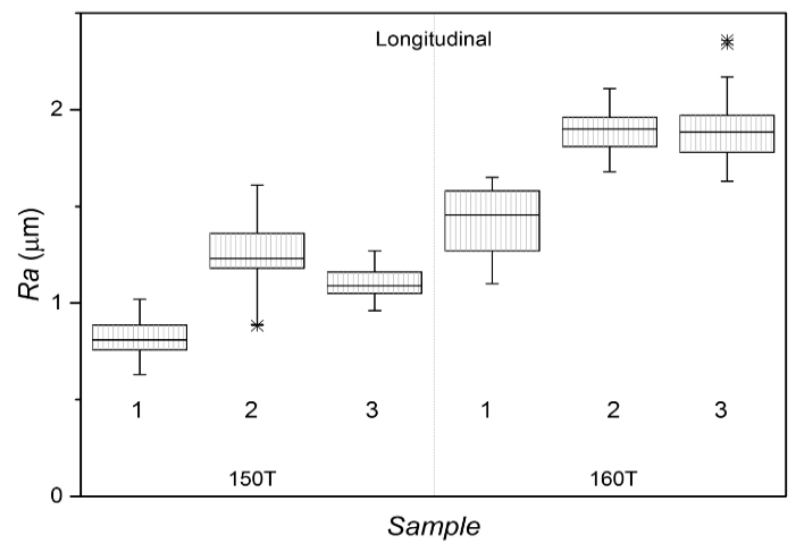

Fig. 5 Box plots of temperature dependent thermally debound surfaces $150 T$ and $160 T$ with respect to the $R_{a}$ parameter - longitudinal direction
Zero hypothesis $H_{0}$ is denied on the confidential level $0.95 \%$, i.e. we suppose that the differences in the investigated surfaces are due to the changes in the processing conditions (temperature).

The same conclusion has been made for the samples moulded at two different temperatures and debound by a combined solvent/thermal route (150ST and 160ST) in the longitudinal direction (Fig. 6):

- $H_{0}: M_{R_{a_{l}}}($ Sample 150ST number 1$)=$ $M_{R_{a_{l}}}($ Sample 150ST number 2$)=$ $M_{R_{a_{l}}}($ Sample 150ST number 3$)=$ $M_{R_{a_{l}}}($ Sample 160ST number 1$)=$ $M_{R_{a_{l}}}($ Sample $160 S T$ number 2$)=$ $M_{R_{a_{l}}}($ Sample 160ST number 3$)$

- $H_{A}: N O N$

- $p=0$

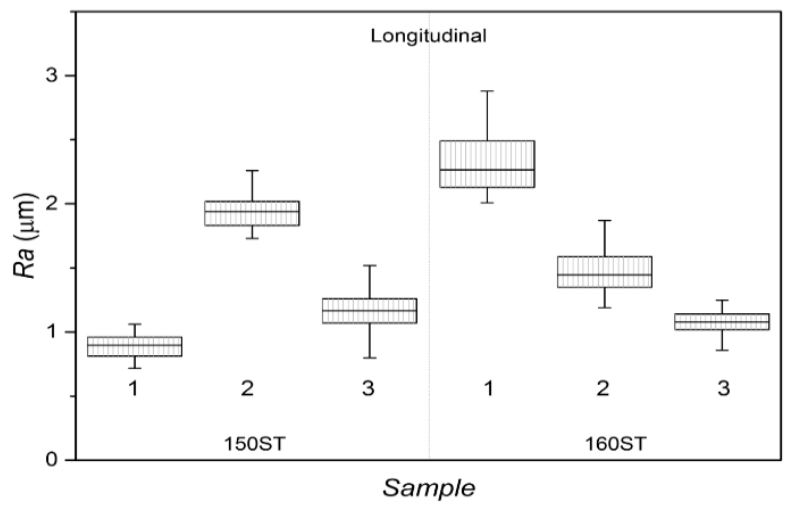

Fig. 6 Box plots of temperature-dependent thermal/solvent debound surfaces 150ST and 160ST with respect to the $R_{\text {a }}$ parameter - longitudinal direction

Similarly for both process conditions in transit use direction (Figure 7a, b):

- $H_{0}: M_{R_{a_{t}}}($ Sample 150 T number 1$)=$ $M_{R_{a_{t}}}($ Sample 150T number 2$)=$ $M_{R_{a t}}($ Sample 150T number 3$)=$ $M_{R_{a_{t}}}($ Sample $160 T$ number 1$)=$ $M_{R_{a_{t}}}($ Sample $160 T$ number 2$)=$ $M_{R_{a_{t}}}$ (Sample 160T number 3 )

- $H_{A}: N O N$

- $p=0$

and

- $H_{0}: M_{R_{a_{t}}}($ Sample 150ST number 1$)=$ $M_{R_{a_{t}}}($ Sample 150ST number 2$)=$ $M_{R_{a_{t}}}($ Sample 150ST number 3$)=$ $M_{R_{a_{t}}}($ Sample 160ST number 1$)=$ $M_{R_{a_{t}}}($ Sample 160ST number 2$)=$ $M_{R_{a_{t}}}$ (Sample 160ST number 3 )

- $H_{0}=N O N$

- $p=0$ 

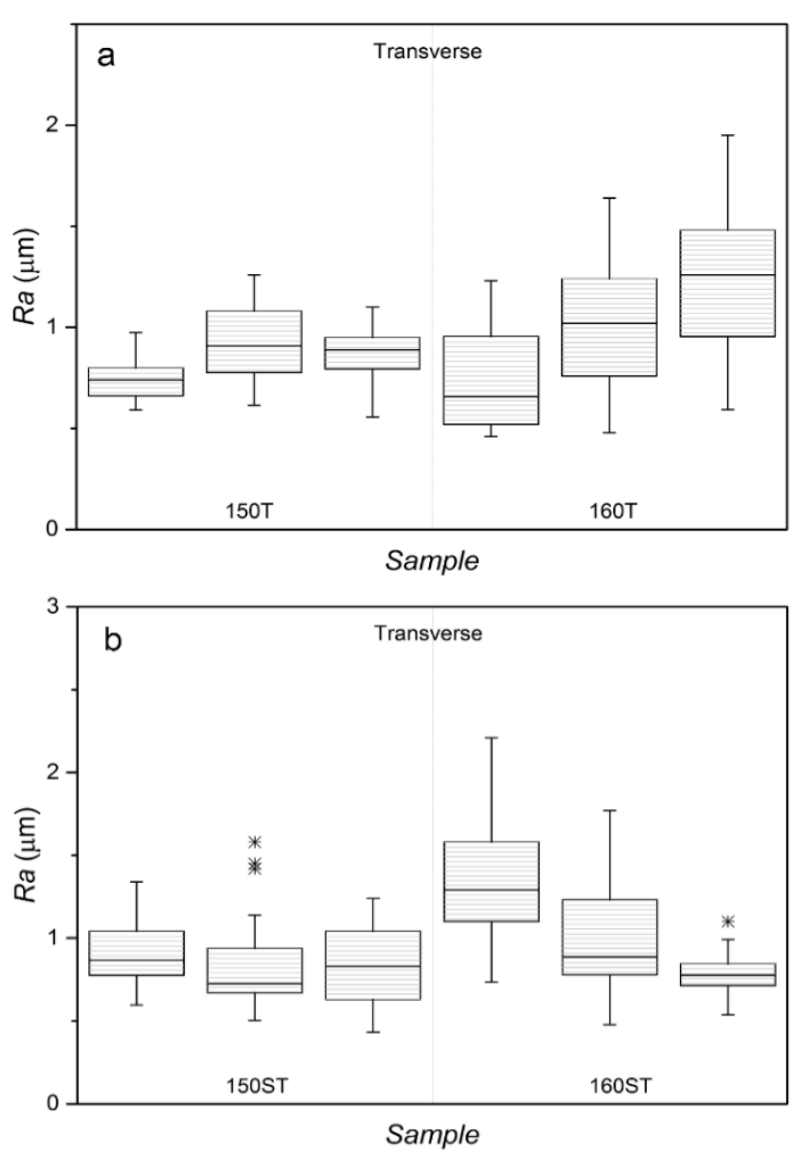

Fig. 7 Box plots of temperature dependent thermally (a) and thermal/solvent (b) debound surfaces with respect to the Ra parameter - transverse direction

Kruskal -Wallis method confirmed on the confidential level $0.95 \%$ (i.e. $5 \%$ error) that the medians of selected samples to search the effect of moulding temperature $\left(150{ }^{\circ} \mathrm{C}\right.$ or $\left.160{ }^{\circ} \mathrm{C}\right)$, as well as the influence of debinding route, do not vary at random. Instead, they are dependent on the processing conditions. Thus, the surface properties might be related to the processing conditions, and based on this knowledge, the process can be optimised. Further, if the samples were produced differently, we may suppose that the changes in medians signify the change in a processing condition.

Taking into consideration the issues connected to the amplitude parameters of the surface roughness ( $R p, R v$, $R a$ ), it seems that the quantification of the surface roughness might improve if the cumulative probability of values in the selected range $(1 \mathrm{~mm})$ will be employed. It is called a material profile or Abbott-Firestone curve. The samples of the surfaces prepared at two different temperatures and debound thermally (150T, 160T), as well as those treated with a combined thermal/solvent debinding (150ST, 160ST), serve as examples for Abbott-Firestone evaluation, Fig. 8.

As can be seen from Figs. 4 - 7, the scatter values, which represent repeatability, show considerable uniformity in the individual quartiles of the presented graphs. Only the cases such as Fig. 7a, the box plot of parameter $R a$ for 160T shows a mild, and thus statistically insignificant, positive skewness. Statistically insignificant skewness can be observed also in the histograms in Figure 8.
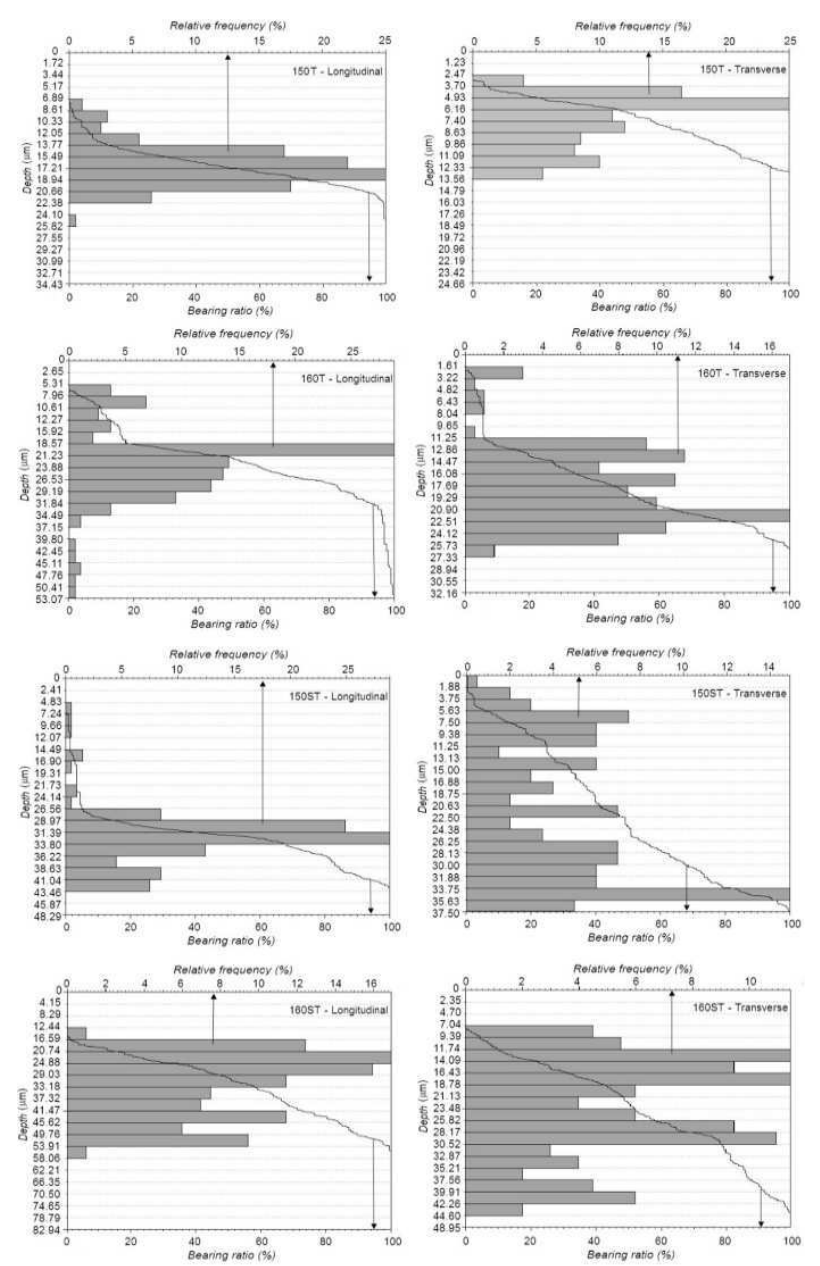

Fig. 8 Abbott-Firestone curves of cumulative probabilities of tested surfaces differing in temperature and debinding route

Based on these curves of the cumulative probabilities of the parameters values in $1 \mathrm{~mm}$ length, it is much easier to detect the character of the surface resulting from the processing conditions during PIM, especially on demands of its flatness or pointedness. This method is also less time-consuming. The evaluation was provided on $R \mathrm{mr}$ parameters according to ISO 4287 at 20 and $60 \%$.

From Fig. 5 it seemed that the surfaces obtained at lower moulding temperature $\left(150{ }^{\circ} \mathrm{C}\right)$ are smoother in both longitudinal direction ( $x$-axis) as well as transverse direction ( $y$-axis). However, cumulative parameters (Abbott-Firestone curves) may intercept more than $R \mathrm{a}, R \mathrm{p}$ and $R \mathrm{v}$ amplitude parameters based on arithmetic. Abbott-Firestone curves include the characteristics of the profile shapes. This means that the method is suitable for the evaluation of the individual samples among each other, and simultaneously, the interception of the influence of the processing conditions. Figure 8 shows that the curves of the surfaces moulded at $150{ }^{\circ} \mathrm{C}$ decline much faster than those obtained at $160{ }^{\circ} \mathrm{C}$. A steeper curve means low accumulation, and thus a sharp profile, which should be avoided whenever the smooth surface of the part is desired. In this respect, the final conclusion is that the higher (not lower) temperature of injection moulding results in the more suitable surface structure of the sintered item investigated. 


\section{Conclusion}

Contactless scanning of the surfaces of aluminium oxide parts produced via powder injection moulding followed with the thorough statistical analysis has been carried out with the aim to investigate the influence of processing parameters - moulding temperature and debinding route - on the resulting sintered surface of these items. First, surface parameters $R \mathrm{p}, R \mathrm{v}$, and $R \mathrm{a}$ obtained from the contactless scanning were treated with Anderson-Darlin normality test showing that the sintered ceramic surfaces contain not only accidental in homogeneities. Then, Kruskal-Wallis statistical approach has been employed for the interception of the influence of the processing conditions confirming that the particular surface roughness parameters $(R \mathrm{p}, R \mathrm{v}, R \mathrm{a})$ have the different median values in the sample groups.

Finally, Abbott-Firestone cumulative curves were found to be suitable for the evaluation of the individual samples among each other, and simultaneously, the interception of the influence of the processing conditions.

\section{References}

[1] KUČERA, V. \& DALIBOR, V. (2018). Processing of Al-Si waste contaminated with iron by powder metallurgy, Manufacturing Technology, vol. 18 , no. 1, pp. 61-65.

[2] HUBA, J., SANETRNIK, D., HNATKOVA, E., HAUSNEROVA, B. \& DVORAK, Z. (2016). New application of powder injection molded product in medical field, Manufacturing Technology, vol. 16, no. 1, pp. 94-98.

[3] USAMA, M.A., JEFFREY, R.A. (2011). A review of micro-powder injection moulding as a microfabrication technique. J. Micromech. Microeng. 21, 1-22 (2011)

[4] TAY, B.Y., LIU, L., LOH, N.H., TOR, S.B., MURAKOSHI, Y., MAEDA, R. (2005). Surface roughness of microstructured component fabricated by $\mu$ MIM. Mater. Sci. Eng. 396, 311-319 (2005)

[5] LIU, L., LOH, N.H., TAY, B.Y., TOR, S.B., MURAKOSHI, Y., MAEDA, R. (2007). Effects of thermal debinding on surface roughness in micro powder injection molding. Mater. Lett. 61, 809-812 (2007)

[6] SUPRIADI, S., BAEK, E.R., CHOI, C.J., LEE, B,T. (2007). Binder system for STS 316 nanopowder feedstocks in micrometal injection molding. $J$. Mater. Process. Technol. 187-188, 270-273 (2007)

[7] ROTA, A. (2002). New features in material issues for metallic micro components by MIM. Proc. PM2TEC pp 10/49-57 (2002)
[8] YIN, H., JIA, C., QU, X. (2008). Micro powder injection molding-large scale production technology for micro-sized components. Sci. China Ser. E: Technol. Sci. 51, 121-6 (2008)

[9] PIOTTER, V., FINNAH, G., ZEEP, B., RUPRECHT, R., HAUSSELT, J. (2007). Metal and ceramic micro components made by powder injection molding. Mater. Sci. Forum. 534-536, 373-376 (2007)

[10] GERMAN, R.M. (2009). Medical and dental applications for microminiature powder injection moulding (microPIM) - a roadmap for growth. PIM Int. 3, 21-29 (2009)

[11] LI, S.G., FU, G., READING, I., TOR, S.B., LOH, N.H., CHATURVEDI, P., YOON, S.F., YOUCEF-TOUMI, K. (2007). Dimensional variation in production of high-aspect-ratio micro-pillars array by micro powder injection molding. Appl. Phys. A-Mater. 89, 721-728 (2007)

[12] ŠČURY, J. \& PASTIRČÁK, R. (2016). Effect of technological parameters on the heat transfer coefficient in alloy $\mathrm{AlCu} 4 \mathrm{Ti}$ using squeeze casting technology, Manufacturing Technology, vol. 16, no. 3, pp. 622-626.

[13] HAUSNEROVA, B., SANETRNIK, D., PONIZIL, P. (2013). Surface structure analysis of injection molded highly filled polymer melts. Polym. Comp. 34, 1553-1558 (2013)

[14] ZRAK. A.. MEŠKO. J.. SLÁDEK. A.. VICEN. M. (2016). Evaluation of Properties from the Cutting Surface after Applying Laser Beam Technology Using Different Scales of Cutting Speed. In: Manufacturing Technology. Vol. 16. No. 6. pp. 1404 - 1408. UJEP. Czech Republic.

[15] BOTKO, F., HATALA, M., MiTAlOVA, Z., CEP, R., RIMAR, M., BERNAT, A. \& VYBOSTEK, J. (2018). Qualitative evaluation of machined surface of aluminum alloy $\mathrm{AlCu} 4 \mathrm{Mg} 1$ depend on feed rate, Manufacturing Technology, vol. 18 , no. 2, pp. 201-207

[16] ŠLAPÁKOVÁ, M., KŘIVSKÁ, B., GRYDIN, O. \& CIESLAR, M. (2018). The influence of casting methods on microstructure of Al-Mg-Sc-Zr alloy, Manufacturing Technology, vol. 18, no. 1, pp. 130-134.

[17] JINFENG ZHANG, CHAO FENG, YUNHUI MA, WEI TANG, SHUAI WANG, XIN ZHONG. (2017). Non-destructive analysis of surface integrity in turning and grinding operations (2017) Manufacturing Technology, 17/3, pp. 412-418. 